\title{
News in periodical medical publications - The case of free journals (open journals)
}

\author{
Benjamín Moncada \\ Universidad Autónoma de San Luis Potosí, Hospital Central Dr. Ignacio Morones Prieto, San Luis Potosí, S.L.P., Mexico.
}

\section{Dear Sir,}

Medicine and biological sciences current development of have led to high complexity, making them inaccessible in the entirety of their diagnostic, pathogenic, and therapeutic aspects to the physician, who requires adequate and affordable continuing medical education sources to keep updated and thereby benefit patients under his/her care. One of the best resources at hand for this purpose is periodical medical publications. These elements are quite numerous; most of them referred to one particular specialty and a lesser extent there are general journals. Their quality has been earned with the passage of time, and there are even comparative indices of this quality.

Unfortunately, over the last decade, a situation has occurred that seems to seriously jeopardize the quality of the information that can reach the physician: Open access journals ${ }^{1}$. In one decade, their number has increased from a couple of dozens to thousands in the world.

In the traditional form, a reader that is interested in one particular article must possess the journal where it appears, or have access, for example, to a login ID and password that may be provided by his/her institution. Should this option not exist, then the purpose would be served by paying the publishing house a certain fee to have access to the article of interest. Conversely, in the case of open access journals, as their name indicates, the reader is not forced to pay any fee, but the one who pays (and not a small amount) is the author of the article, which in principle appears to be excellent and fair. The problem arises when open access journals publishers are observed to resolve publication acceptance in very short time, even inviting authors to submit other manuscripts establishing an acceptance deadline and a subsequent publication date, both with very short time periods. It is thus observed that these publishing houses desire is quantity and, of course, the larger the number of proposals, the higher the revenue to be obtained by them. Where does all this lead to? To a decrease in the quality of the materials published under this system.

Some of the strategies that are being used to mislead the reader are, for example, giving their publications an almost identical name to that of an already existing publication, which prompts the reader to think that these are formal, traditional journals. Another one, asking an investigator to take charge of the development of a future issue, for example, at 4 months distance, with collaborators being hired to take care of the journal's issue usual extension and incentives (discounts) being offered for the moment these investigators want to publish in that journal. Often, they also use non-traditional impact indices, characterized for granting high figures.

In a recent publication ${ }^{2}$, the problem of open access journals is addressed, expressing great concern about it and calling the medical class to fight it, especially by taking collective measures. One strategy would be rising collective awareness of this problem within the medical population, bringing it up frequently, and drawing the attention on the deterioration in medical education in general (and in continuing medical education in particular) that would occur should this continue. In this aspect, the National Academy of Medicine could play an important role. It could also suggest that when a person's CV is examined for diverse purposes, such as having a sufficient number
Correspondence:

Benjamín Moncada

E-mail: moncadab@uaslp.mx
Date of modified version reception: 23-03-2017

Date of acceptance: 26-04-2017

DOI: 10.24875/GMM.M17000033
Gac Med Mex. 2017;153:474-475

Contents available at PubMed www.gacetamedicademexico.com 
of publications to achieve a goal, not taking those published in open access journals into account.

One way to "fight" open access journals would be by conventional publications trying to reduce in as much as possible the time they take between receiving an article and expressing the decision to publish or not, since this long wait, compared with the brief or extremely brief time offered by open access journals is an incentive for authors to lean toward the latter.

Recently, a variant of the so-called open journals, known as "predatory journals," where the described anomalies are accentuated, has been established ${ }^{3}$.

There are some situations that have to be taken into account as something not corresponding to those expressed comments and that are seemingly valid.
There are quality publications that allow to be freely accessed, usually sometime after the issue under consideration first appearance. On other occasions, when publishing an article that includes images, the publisher offers the option of publishing them in color, but with a cost involved for this reason; the author has the option to choose black and white or color, and in the latter case, pay.

\section{References}

1. Butler D. Investigating journals: The dark side of publishing. Nature. 2013;495:433-5.

2. Moher D, Moher E. Stop predatory publishers now: Act collaboratively. Ann Intern Med. 2016;164:616-7.

3. Shamseer L, Moher D, Madueke O, et al. Potential predatory and legitimate biomedical journals: Can tell you the difference? A cross sectional comparison. BMC. 2007;15:28. 